\title{
Early childhood caries and its relationship with perinatal, socioeconomic and nutritional risks: a cross-sectional study
}

\author{
Valdeci Elias dos Santos Junior ${ }^{1,2^{*}}$, Rebeca Maria Brasileiro de Sousa', Maria Cecília Oliveira', \\ Arnaldo França de Caldas Junior ${ }^{1}$ and Aronita Rosenblatt ${ }^{1}$
}

\begin{abstract}
Background: Socioeconomic, perinatal and other life cycle events can be important determinants of the health status of the individual and populations. This study aimed to assess the prevalence of early childhood caries (ECC), perinatal factors (gestational age, teenage pregnancy and birth weight), family income and nutritional risk in children.

Methods: A cross-sectional study in which 320 children were examined according to the criteria established by the World Health Organization. A previously validated questionnaire was used to obtain information from parents and guardians about family income, gestational age and birth weight. To check the nutritional risk, we used the criteria provided by the CDC (Center for Disease Control). For Statistics, Pearson's, chi-square and the multivariate Poisson analyses were used to determine the association among variables.
\end{abstract}

Results: Approximately $20 \%$ of children had ECC, and the Poisson multivariate analyses indicated that family income $(p=0.009)$, birth weight $(p<0.001)$ and infant obesity $(p<0.001)$ were related to the increase of ECC, and gestational age was not significantly associated with ECC $(p=0.149)$. Pregnancy in adolescence was not included in the regression analyses model because it was not statistically significant in the chi-square test $(p>0.05)$.

Conclusion: The prevalence of ECC was related to low family income, premature birth and infant obesity.

Keywords: Dental caries, Child, Obesity, Teenage pregnancy, Birth weight, Prematurity

\section{Background}

Early childhood caries is a common public health problem in developing countries, where malnutrition is still an issue. This pattern of decay develops very rapidly in preschoolers, affecting tooth surfaces that are naturally caries-prone $[1,2]$. Whereas the disease is influenced by social context, this discussion goes beyond the boundaries of oral health issues to social equality [3].

Adverse perinatal factors result in poor oral health conditions, considering that low birth weight children tend to develop enamel and dentine defects, which facilitates the adhesion and colonization of cariogenic bacteria in poorly calcified dental tissue $[2,4]$. The current literature

\footnotetext{
* Correspondence: valdeciodonto@gmail.com

'Department of Paediatric Dentistry, Faculty of Dentistry, University of Pernambuco, Recife, Brazil

${ }^{2}$ Rua São Sebastião, 417 \#101 CEP 54410500, Jaboatão dos Guararapes, PE,
} Brazil

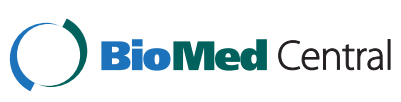

(c) 2014 dos Santos Junior et al.; licensee BioMed Central Ltd. This is an Open Access article distributed under the terms of the Creative Commons Attribution License (http://creativecommons.org/licenses/by/2.0), which permits unrestricted use,

distribution, and reproduction in any medium, provided the original work is properly credited. The Creative Commons Public Domain Dedication waiver (http://creativecommons.org/publicdomain/zero/1.0/) applies to the data made available in this article, unless otherwise stated.
[3-5] indicates that there is a strong association between enamel defects, prematurity and low birth weight [6].

According to The World Health Organization [7], adolescent pregnancy is a health risk that affects mothers and newborns that also increases disadvantageous social and biological life events [7]. Prematurity and low birth weight is closely related to infant mortality, perinatal infections and the poor growth and development of children [8].

Therefore, this study aimed to assess the prevalence of early childhood caries and its association with perinatal factors, such as gestational age, pregnancy and birth weight, along with family income and nutritional risk, to produce incremental evidence-based knowledge to update the state of care in a fast-growing society. 


\section{Methods}

This is an epidemiological study conducted in Cabo de Santo Agostinho, in the southeastern part of Pernambuco, Brazil, which has a population of approximately 185,123 inhabitants [9]. The sample was comprised of 320 preschoolers aged from three to four years who were attending municipal kindergarten.

The calculation of sample size considered that a previous pilot study on ECC indicated a prevalence of 22.3\%, with a 95\% confidence interval and a 5\% standard error. This resulted in a sample of 266 children, and after adding $20 \%$ to avoid data loss, a sample size of 320 children was established.

The pilot study was conducted with $10 \%$ of the sample in the yards of the schools, in a knee-to-knee position, with natural light and using a dental mirror and wooden spatula. Children received oral hygiene instruction and supervised tooth brushing before the exam. The children who took part in this trial were included in the final sampling.

This study was approved by the Ethics Committee of the University of Pernambuco. (Protocol No. 119/12). Consent for undertaking the research was obtained from the school principals, and consent to perform the examinations came from the parents or guardians. Only the children of those parents or guardians who returned the signed permission forms were included in the study.

The examinations were performed by a calibrated examiner for visual exam following criteria established by the World Health Organization [10]. Kappa coefficients for intra-examiner agreement was $\mathrm{K}=0.90$.

Cavitated carious lesions in children younger than 71 months were classified as ECC, according by Drury et al. [11]. The individuals with syndromes that impact the oral cavity were excluded from the sample to avoid confounding factors.

In addition to the oral examination, children were measured and weighed to assess nutritional risk as proposed by the CDC (Center for Disease Control) [12], which analyses the BMI (Body Mass Index) curve by age and sex from 2-19 years of age. The child was considered to be underweight when the value was below the 5 th percentile, normal weight when between the 5 th (inclusive) and below the 85th, overweight when between the 85th (inclusive) and 95th and obese when above the 95th percentile. The measurement of body weight was recorded by the researcher, with the child standing with minimal clothing without shoes on a portable calibrated scale with a precision of $100 \mathrm{~g}$, and the height was measured with a tape strip scale.

The examiners administered a questionnaire, which was previously validated in a pilot study, to parents and guardians at the pick-up time at school in order to obtain information on family income. To determine the gestational age and birth weight, we accessed the vaccination and the local maternity hospital records that followed the WHO criteria [13], indicating preterm to be less than 37 weeks. The WHO criteria [8] for adolescent pregnancy included girls from 10 to 19 years of age. The classification for birth weight included very low birth weight (less than $1500 \mathrm{~g}$ ), low birth weight (less than $2500 \mathrm{~g}$ ) and normal birth weight (equal to or greater than $2500 \mathrm{~g}$ ).

After data collection and the categorization of variables, we created a database for statistical analysis using SPSS (Statistical Package for Social Sciences) version 17. To test the association between two categorical variables, the chisquared test was used. To explain the prevalence of early childhood caries and its association with the other risk factors, we chose the Poisson regression test, which is similar to logistic regression, with the advantage that the prevalence ratio (PR) is more stable and the value for $\mathrm{OR}$ varies in a smaller range. The margin of error was $5 \%$.

\section{Results}

Three hundred and twenty preschoolers were evaluated. There were no losses or drop-outs because the schools were not very far from each other and we could always return to see those that failed to attend school regularly. The mean age was 43.2 months. The presence of ECC was registered as yes/no and results showed that $20 \%$ of children had this type of dental disease.

The prevalence of ECC was shown to be related to low family income, low birth weight, infant obesity and shorter gestational age $(\mathrm{p}<0.05)$. There was a higher prevalence of ECC among children with low birth weight $(80.4 \%)$ than those born with a normal weight (9.9\%) and those born preterm (82.8\%) compared with those born at term (13.7\%) (Table 1). Twenty-five percent (80 cases) involved adolescent pregnancy. Table 2 shows the results for the multivariate Poisson regression analysis to explain the association of early childhood caries with the following variables: family income, birth weight, gestational age and nutritional risk. For significant variables, the probability of the presence of early childhood caries increased if the child was underweight at birth $(\mathrm{p}<0.001)$, demonstrated infant obesity $(\mathrm{p}<0.001)$ or exhibited a family income less than or equal to $\$ 282.00$ ( $\mathrm{p}=0.009$ ).

Pregnancy in adolescence was not included in the statistical regression model because it did not show a statistically significant difference in the person's chi-squared test $(\mathrm{p}>0.05)$.

\section{Discussion}

The present study is in accordance with previous reports [14-16] that describe the strength of the relationship between decreases in family income, the risk of children developing ECC and the impact of this social 
Table 1 Early childhood caries, family income, adolescent pregnancy, birth weight, gestational age and nutritional risk

\begin{tabular}{|c|c|c|c|c|c|c|c|c|}
\hline \multirow{3}{*}{ Variable } & \multicolumn{4}{|c|}{ Evaluation ECC } & & & \multirow{3}{*}{$P$ value } & \multirow{3}{*}{ PR (IC a 95\%) } \\
\hline & \multicolumn{2}{|c|}{ YES } & \multicolumn{2}{|c|}{ NO } & \multicolumn{2}{|c|}{ TOTAL } & & \\
\hline & $\mathbf{N}$ & $\%$ & $\mathbf{n}$ & $\%$ & $\mathbf{N}$ & $\%$ & & \\
\hline TOTAL & 64 & 20.0 & 256 & 80.0 & 320 & 100.0 & & \\
\hline \multicolumn{9}{|l|}{ - Family income } \\
\hline No Income & 14 & 34.1 & 27 & 65.9 & 41 & 100.0 & $p^{(1)}=0.01^{*}$ & 3.34 (1.71 to 6.51$)$ \\
\hline Less than or equal to minimum wage ( $\$ 282.00$ ) & 37 & 24.3 & 115 & 75.7 & 152 & 100.0 & & 2.38 (1.32 to 4.27$)$ \\
\hline More than one minimum wage & 13 & 10.2 & 114 & 89.8 & 127 & 100.0 & & 1,00 \\
\hline \multicolumn{9}{|l|}{ - Adolescent pregnancy } \\
\hline Yes & 15 & 18.7 & 65 & 81.3 & 80 & 100,0 & $p^{(1)}>0.18$ & $1.16(0,63$ to 2,01$)$ \\
\hline No & 38 & 16 & 204 & 84 & 240 & 100,0 & & 1,00 \\
\hline \multicolumn{9}{|l|}{ - Birth weight } \\
\hline Low & 37 & 80.4 & 9 & 19.6 & 46 & 100.0 & $\mathrm{p}^{(1)}<0.01^{*}$ & $8.16(5,55$ to 12.00$)$ \\
\hline Normal & 27 & 9.9 & 247 & 90.1 & 274 & 100,0 & & 1.00 \\
\hline \multicolumn{9}{|l|}{ - Gestacional age } \\
\hline Premature & 24 & 82.8 & 5 & 17.2 & 29 & 100.0 & $\mathrm{p}^{(1)}<0.01^{*}$ & 6.02 (4.32 to 8.39$)$ \\
\hline Term & 40 & 13.7 & 251 & 86.3 & 291 & 100.0 & & 1.00 \\
\hline \multicolumn{9}{|l|}{ - Nutritional Risk } \\
\hline Underweight & 2 & 100,0 & - & - & 2 & 10,0 & $\mathrm{p}^{(1)}=0.01^{*}$ & $* *$ \\
\hline Normal weight & 57 & 18.4 & 253 & 81.6 & 310 & 100.0 & & \\
\hline Obesity & 5 & 62.5 & 3 & 37.5 & 8 & 100.0 & & \\
\hline
\end{tabular}

(*)Significant association at 5.0\%.

$\left.{ }^{* *}\right)$ Unable to determine due to the occurrence of null frequencies.

(') By chi-square test.

determinant of health. Lagreca [17] conducted a survey that reported the incidence of dental caries in relation to the socioeconomic status that indicated that in Brazil, children whose family income was in the range of the minimum wage, caries incidence was
$57 \%$ higher than those whose family income was above four times the minimum wage. Then, with the speed of the production and the diffusion of new and advanced science, it would be anachronistic to continue to refer to the aetiology of dental caries exclusively by the

Table 2 Results of multivariate poisson regression to the prevalence of early childhood caries

\begin{tabular}{|c|c|c|c|}
\hline \multirow[b]{2}{*}{ Variables } & \multicolumn{2}{|c|}{ PR and IC $95,0 \%$} & \multirow[b]{2}{*}{$P$ value } \\
\hline & Univariate & Adjusted & \\
\hline \multicolumn{4}{|l|}{ - Family income } \\
\hline No & $3.58(1.80$ a 7.12$)$ & $2.42(1.20$ a 4.88$)$ & $p=0.009^{*}$ \\
\hline Less than or equal to minimum wage ( $\$ 282.00$ ) & $2.50(1.36$ a 4.61$)$ & $2.15(1,30$ a 3.54$)$ & \\
\hline More than one minimum wage & 1,00 & 1,00 & \\
\hline \multicolumn{4}{|l|}{ - Birth weight } \\
\hline Low & $8.40(5.66$ a 12.46$)$ & 7.09 (3.91 a 12.86) & $p<0.001^{*}$ \\
\hline Normal & 1,00 & 1,00 & \\
\hline \multicolumn{4}{|l|}{ - Gestational age } \\
\hline Premature & $6.11(4.35$ a 8.58$)$ & 1.39 (0.89 a 2.19$)$ & $p=0.149$ \\
\hline Term & 1.00 & 1.00 & \\
\hline \multicolumn{4}{|l|}{ - Risk nutritional } \\
\hline Normal weight & 1.00 & 1.00 & $p<0.001^{*}$ \\
\hline Obesity & $3,40(1.89$ a 6.11$)$ & $6,24(3.06$ a 12.72$)$ & \\
\hline
\end{tabular}

(*):Significant at 5.0\%. 
intersection of primary factors, such as microbiota and host substrate.

According to the Brazilian Institute of Geography and Statistics-IBGE [9], 53.9 million Brazilians live in extreme poverty, which accounts for $31.7 \%$ of the population. In the northeastern part of the country, $76.5 \%$ of the families earn less than the minimum wage, which is approximately that found in the present study: $60.3 \%$ of families living in poverty.

From the perspective of health inequality, Marmot, Bell and Goldblatt [18] conceptualized that there is a convergence between unfavourable socioeconomic conditions and the presence of diseases. Corroborating this concept, the present study indicated that children from families that earn less than \$ 282 are at a higher risk for ECC.

It has been suggested that human life events can alter stable biological mechanisms and turn them into a genetic legacy process called incorporation of biologic features [19]. From this perspective, the traditional etiological factor for caries, which involves the association of high sugar intake [20,21], poor oral hygiene [22-24], lack of exposure to fluoride and perinatal disturbances related to enamel defects $[21,24]$, which could influence genetic legacy.

Currently, reports [25,26] show that prematurely born individuals have poor mineralization of the teeth and poorer oral health indicators, supporting the evidence of the role played by enamel defects in the development of ECC. Moreover, in a 7-year cohort study, Targino et al. (2011) [24] revealed that enamel defects constitute a risk factor for the development of early childhood caries. Thus, perinatal factors such as low birth weight and gestational prematurity are risk factors for the development of early childhood caries.

Due to the worldwide increase in childhood obesity across populations and the polarization of dental caries, several studies $[27,28]$ reported on the associations of obesity and infant caries; however, the results of these studies are still controversial. In 2006, a systematic review [29] found only one study that consistently showed a direct association between obesity and dental caries with a high level of evidence. The findings of this work show an association between childhood obesity and dental caries, as in some previous epidemiological and cohort studies $[27,28]$. The results of this study indicate that it is possible that the conflicting results could be related to variations in the way data were collected, the socioeconomic status of the sample, the parameters used to analyse nutritional status and caries diagnosis [29].

Although the present research indicated no significant association between adolescent pregnancy and ECC, perinatal complications arising from the lack of biological development of teenagers are themselves risk factors for preterm and low birth weight children [25], which were identified as risk factors for ECC [29].

\section{Conclusion}

The prevalence of ECC was shown to be related to low family income, premature birth and infant obesity. Thus, this study showed that socio-economic factors and perinatal events are important determinants for the status of oral health in children.

\section{Bullet points}

- It is essential to monitor the prevalence of early childhood caries and its risk factors.

- Low family income, premature birth and infant obesity should be considered as risk factors for the development of ECC.

\section{Competing interest}

This study was funded by the Ministry of Education of Brazil. Thus, there is no conflict of interest, nor any such interference with the results of this article.

\section{Authors' contributions}

VSJ participated in the study design and epidemiological data analysis and drafted the manuscript. CMC facilitated the field work and data collection. $\mathrm{RMB}$ was the main dentist who examined and diagnosed all of the children $A R$ and AFCJ were the main supervisors, and they guided the study design, performed statistical analysis and drafted the manuscript. All authors read and approved the final manuscript.

\section{Acknowledgements}

The authors would like to express their gratitude to the teachers, school staff and parents who participated in the survey. This study was supported by a grant from the Brazilian Ministry of Education (CAPES).

Received: 2 January 2014 Accepted: 1 May 2014

Published: 6 May 2014

\section{References}

1. Suckling GW: Development defects of enamel - historical and present day perspectives of their pathogenesis. Adv Dent Res 1989, 3:87-94.

2. Horowitz HS: Research issues in early childhood caries. Community Dent Oral Epidemiol 1998, 26(Suppl 1):67-81.

3. Fearne JM, Bryan EM, Elliman AM, Brook AH, Wlliams DM: Enamel defects in the primary dentition of children born weighing less than $2000 \mathrm{~g}$. Br Dent J 1990, 168:433-437.

4. Goodman AH, Martinez C, Chavez A: Nutritional supplementation and the development of linear enamel hypoplasias in children from Tezonteopan. Am J Clin Nutr 1991, 53:773-781.

5. Tesch C, Oliveira BH, Leão A: Measuring the impact of oral health problems on children's quality of life: conceptual and methodological issues. Cad Saude Publica 2007, 23:2555-2564.

6. Lai PY, Seow WK, Tudehope DI, Rogers Y: Enamel hypoplasia and dental caries in very-low birthweight children: a case-controlled, longitudinal study. Pediatr Dent 1997, 19:42-49.

7. WHO: World Health Organization Health needs of adolescents. Report of a Committee of Experts from WHO. Geneva: WHO; 1997:55p.

8. Guimarães AAG, Velásquez-Meléndez G: Low birth weight determinants from the Born Alive National Surveillance System in Itaúna, Minas Gerais. Rev Bras Saúde Matern Infant 2002, 2:283-290.

9. IBGE: Brazilian Institute of Geography and Statistics. Census 2010; 2013. http://www.censo2010.ibge.gov.br/resultados.

10. WHO: World Health Organization Basic Epidemiological survey of oral health. Manual. 4th edition. Geneva: World Health Organization; 1997. 
11. Drury TF, Horowitz AM, Ismail Al, Msertens MP, Rozier RG, Selwitz RH: Diagnosing and reporting early childhood caries for research purposes. J Public Health Dent 1999, 59:192-197.

12. National Center for Health Statistics: Data on child health; 2013. www.cdc. gov/nchs/fastats/children.htm.

13. WHO: World Health Organization international statistical classification of diseases and related health problems; 1995.

14. Corrêa-Faria P, Martins-Júnior PA, Vieira-Andrade RG, Marques LS, Ramos-Jorge ML: Factors associated with the development of early childhood caries among Brazilian preschoolers. Braz Oral Res 2013, 27:356-362.

15. Costa LR, Daher A, Queiroz MG: Early childhood caries and body mass index in young children from low income families. Int J Environ Res Public Health 2013, 10:867-878.

16. Hooley M, Skouteris H, Boganin C, Satur J, Kilpatrick N: Parental influence and the development of dental caries in children aged 0-6 years: a systematic review of the literature. J Dent 2012, 40:873-885.

17. Lagreca BT: Evaluation of risk factors associated with dental caries disease that affect the population of schoolchildren in Xerém-Duque de Caxias [dissertation]. Rio de Janeiro: UNIGRANRIO; 2007.

18. Marmot M, Bell R, Goldblatt P: Action on the social determinants of health. Rev Epidemiol Sante Publique 2013, 61(Suppl 3):S127-S132.

19. Hertzman C, Boyce T: How experience gets under the skin to create gradients in developmental health. Annu Rev Public Health 2010, 31:329-347.

20. Rosenblatt A, Zarzar P: The prevalence of early childhood caries in 12- to 36-month-old children in Recife, Brazil. ASDC J Dent Child 2002, 69:319-324.

21. Milgrom P, Riedy CA, Weinstein P, Tanner ACR, Manibusan L, Bruss J: Dental caries and its relationship to bacterial infection, hipoplasia, diet, and oral hygiene in 6- to 36-month-old children. Community Dent Oral Epidemiol 2000, 28:295-306.

22. Harris $R$, Nicoll AD, Adair PM, Pine CM: Risk factors for dental caries in young children: a systematic review of the literature. Community Dent Health 2004, 21(Suppl 1):71-85.

23. Warren JJ, Weber-Gasparoni K, Marshall TA, Drake DR, Dehkordi-Vakil F, Dawson DV, Tharp KM: A longitudinal study of dental caries risk among very Young low SES children. Community Dent Oral Epidemiol 2009, 37:116-122.

24. Targino AG, Rosenblatt A, Oliveira AF, Chaves AM, Santos VE: The relationship of enamel defects and caries: a cohort study. Oral Dis 2011, 17:420-426.

25. Rythén M: Preterm infants-odontological aspects. Swed Dent J Supp/ 2012. (224):1-106. 2p preceding i-vi.

26. Julihn A, Ekbom A, Modéer T: Maternal overweight and smoking: prenatal risk factors for caries development in offspring during the teenage period. Eur J Epidemiol 2009, 24:753-762.

27. Norberg C, Hallstrom Stalin U, Matsson L, Thorngren-Jerneck K, Klingberg G: Body mass index (BMI) and dental caries in 5-year-old children from southern Sweden. Community Dent Oral Epidemiol 2012, 40:315-322.

28. Oliveira LB, Sheiham A, Bonecker M: Exploring the association of dental caries with social factors and nutritional status in Brazilian preschool children. Eur J Oral Sci 2008, 116:37-43.

29. Kantovitz KR, Pascon FM, Rontani RM, Gaviao MB: Obesity and dental caries- a systematic review. Oral Health Prev Dent 2006, 4:137-144.

\section{Submit your next manuscript to BioMed Central and take full advantage of:}

- Convenient online submission

- Thorough peer review

- No space constraints or color figure charges

- Immediate publication on acceptance

- Inclusion in PubMed, CAS, Scopus and Google Scholar

- Research which is freely available for redistribution

Submit your manuscript at www.biomedcentral.com/submit
C Biomed Central 